\title{
Research on InlandPort Facilities Adaptability Evaluation Indicator System
}

\author{
Yaofeng Xie ${ }^{1}$, Chenglin $\mathrm{Liu}^{2}$, Suyang $\mathrm{Gao}^{3}$, Yan Chen ${ }^{4}$ and Ning Jiang ${ }^{5}$ \\ ${ }^{1-5}$ School of Transportation, Southeast University, Si Pai Lou \#2,Nanjing 210096, China
}

\begin{abstract}
Upgrading engineering of inland simple backward port facilities is urgent and of great significance in the aspect of economy and society. Port facilities adaptability evaluation is the foundation work of the research on upgrading strategy. Based on Anhui inland simple backward port facilities upgrading strategy research, AHP is introduced in the analysis of port facilities adaptability evaluation indicator system. The weights of 40 evaluation indicators are obtained through establishing an AHP structure model, constructing judgment matrixes, checking consistency, and calculating combination weights. By combining the analysis of relevant relationships between the indicators, 16 indicators are selected as indicators of port facilities adaptability evaluation system. The research results lay the foundation for the upgrading strategy research on Anhui inland simple backward port facilities, which can be an essential reference for similar projects.
\end{abstract}

\section{Introduction}

Inland water transportation is an important part of comprehensive transport system and water resource utilization and management system, and it is an essential part of basin economy because of large freight volume, low transportation cost, less ground demand, less energy consumption, and less pollution. Yangtze River, Huai'he River and Xin'an River cut through AnhuiProvince, forming a natural advantage of water transportation. However, some ports lack systematic plan and scientific management, which results in the inefficient utilization of some inland river shoreline resources. Especially for the 600 simple backward berths with 500-ton level or below 500-ton level along the branches of three large drainage, the development level fall behind the development status of local economy and Anhui economy. These simple backward ports have already become negative factor blocking the transformation of Anhui economy.

Based on the development status of Anhui inland simple backward port facilities, port facilities adaptability evaluation system is established to evaluate the ability of port facilities to adapt the change of external environment factors and to keep pace with port development needs. In order to confirm the main indicators of port facilities adaptability evaluation, AHP is introduced to determine the weights of all the evaluation indicators, which is in support of selecting several relatively important indicators from many indicators proposed. AHP is an effective multi-target decision method combining qualitative analys is with quantitative analysis, which is a common method with easy calculation and clear results [1-2].

A lot of researches have been done with AHP in port management,green port development, port logisticand some other relevant areas. Mabrouki $\mathrm{C}$ et al analyzed the problem of operational risk management in port terminal with AHP method[3], P. Zhang et al studied the evaluation indexed system of dangerous good logistics port with AHP[4],Y. Xie et al developed the port ecological suitability evaluation model with AHP[5].

AHP is also widely adopted in indicator management system and decision-making system [6-8] and it is often combined with other methods for instance, expert consults and fuzzy set theory.Chiu.R revealed top five priority attributes of green port operation with Fuzzy AHP model[9].F. Zhu et al evaluated the function of the port logistics with AHP- FCE model[10]. Nevertheless, fewer literatures have been published on the port facilities adaptability evaluation system.

In this paper, MATLAB software is adopted to programmatically deal with judgment, analysis and calculation process of AHP in order to conveniently confirm the weights of port facilities adaptability evaluation indicators and to lay the foundation for the analysis of indicator selection results. The research results by AHP can be a valid reference for establishing port facilities adaptability evaluation system.

\section{Basic rules of AHP}

AHP is a weight decision method proposed by an American scholar named Saaty, T. L in the 1970s. AHP is characterized by making the highest goal hierarchy and resolving the goal hierarchy into small targets in the bottom hierarchy according to the influence indicators, which makes the decision method more convenient. The method combines quantitative analysis with qualitative analysis, using the experience of the decision makers to 
judge the relative importance of each target, which can be effectively used in some problems difficult to adopt quantitative method[11-13]. The basic ideas of AHP are as follows:

(1)According to the properties of the problem and the total target expected to reach, the influence indicators of the decision-making problem are listed. Moreover, an ordered hierarchy is established on the basis of the connection, interaction and membership between the indicators to obtain a multilevel analys is model, which methodizes the decision-making problem.

(2)The subjective judgments of indicator importance are reflected in quantitative way, based on which, judgment matrix is set up by comparing each indicator in the same hierarchy.

(3)The weights of indicators in each hierarchy are calculated by mathematical method.
(4)Through the comprehensive analysis of the hierarchies from low to high, the weights of indicators in the bottom hierarchy which are relative to the highest goal are calculated. The weight of the indicators represents the importance of each indicator, determining the important indicators which influence the highest goal.

\section{Basic steps of AHP}

\subsection{AHP structure model establishment}

The premise of establishing an AHP structure model is to fully understand the problem to be solved, grasp the scope, the indicators of the problem and the relationship and membership of these indicators. On this basis, the involved indicators of the problem are classified, and an AHP structure model figure is shown as Figure. 1.

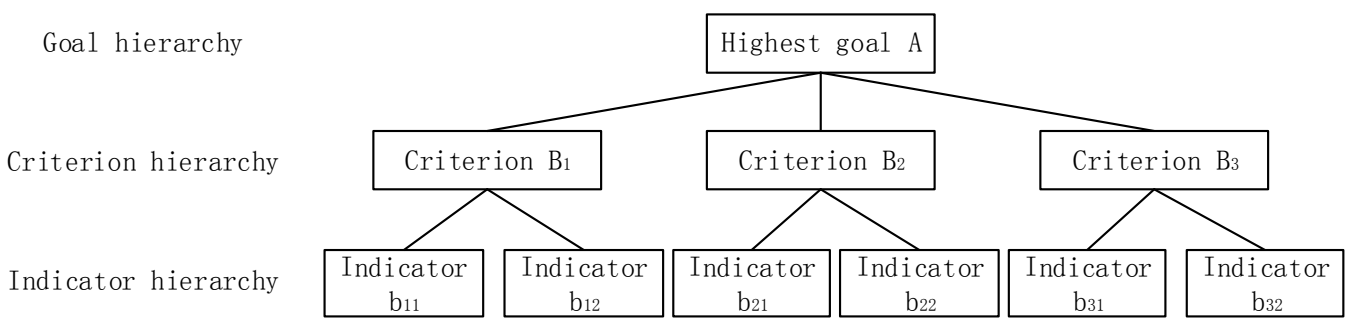

Figure 1. AHP structure model.

\subsection{Judgment matrix construction}

In general, the relative importance of each indicator in indicator hierarchy to criterion hierarchy is different, and the relative importance of each indicator in criterion hierarchy to the highest goal is different. The relative importance of two indicators is difficult to determine, therefore, through comparing these indicators in pairs, judgment matrix can be constructed according to the scale which describes the importance. The judgment matrix reflects the relative importance of indicators in the hierarchy to the specific indicator in the upper hierarchy, which is the basic ground for making decision.
Supposing that the indicator $A_{k}$ of the upper hierarchy is relevant with $\mathrm{n}$ indicators $\left(B=\left\{B_{1}, B_{2}, \ldots \ldots, B n\right\}\right)$ in the lower hierarchy, and bij represents the importance of indicator $B_{i}$ to $B_{j}$ when considering indicator $A_{k}$, all comparison results can be shown as matrix $B=(b i j) n \times n$ in Table 1. According to the characteristic of judgment matrix $B, b i j>0, b i i=1, b i j=b j i(i, j=1,2, \ldots, n)$.

In order to quantify the comparison, the scale method of 1 9 is introduced as shown in Table 2 on the basis of research conclusion proposed by psychologists that the ultimate ability of people in distinguishing the information level is $7 \pm 2$. The value of bij can be $2,4,6$ or 8 if the relative importance is between the levels. The reciprocal is the result of two indicators in reverse comparison.

Table 1.Matrix $B=(b i j) n \times n$

\begin{tabular}{|c|c|c|c|c|c|c|}
\hline$A_{k}$ & $B_{1}$ & $B_{2}$ & $\ldots \ldots$ & $B_{j}$ & $\ldots \ldots$ \\
\hline$B_{1}$ & $b_{11}$ & $b_{12}$ & $\ldots \ldots$ & $b_{1 j}$ & $\ldots \ldots$ \\
\hline$B_{2}$ & $b_{21}$ & $\ldots \ldots$ & $\ldots \ldots$ & $\ldots \ldots$ & \\
\hline$\ldots \ldots$ & $\ldots \ldots$ & $\ldots \ldots$ & $\ldots \ldots$ & \\
\hline$B_{n}$ & $b_{n 1}$ & $\ldots \ldots$ & $\ldots \ldots$ & $\ldots \ldots$ \\
\hline
\end{tabular}

Table 2.Scale method of 1 9

\begin{tabular}{|c|c|c|c|c|c|}
\hline $\begin{array}{c}\text { Comparing } \mathrm{B}_{\mathrm{i}} \\
\text { with } \mathrm{B}_{\mathrm{i}}\end{array}$ & $\begin{array}{c}\text { Equally } \\
\text { important }\end{array}$ & $\begin{array}{c}\text { Weakly } \\
\text { important }\end{array}$ & $\begin{array}{c}\text { Obviously more } \\
\text { important }\end{array}$ & $\begin{array}{c}\text { Demonstratively important } \\
\text { important }\end{array}$ \\
\hline
\end{tabular}




\section{\begin{tabular}{|c|c|c|c|}
\hline $\mathrm{b}_{\mathrm{ij}}$ & 1 & 3 & \\
\hline
\end{tabular} \\ 3.3 Consistency check of Hierarchical single arrangement}

The hierarchical single arrangement weight is the order weight of indicators in this hierarchy to an indicator in the upper hierarchy. Firstly, the characteristic vector solution $\left(W=\left[W_{1}, W_{2}, W_{3}, \ldots \ldots, W n\right]^{T}\right)$ of the judgment matrix $(B=[b i j] n \times n)$ is calculated. Then, the weight $(C=$ $\left.\left[C_{1}, C 2, C_{3}, \ldots \ldots, C n\right]^{T}\right)$ is obtained by normalizing the characteristic root solution.

$$
B W=\lambda_{\max } W(1)
$$

For the problem with many indicators and large scale, due to the complexity of the thing and the one-sidedness of people's cognition, the judgment matrix is not necessarily completely consistent. If the judgment matrix is not completely consistent, mark judgment $B$ as $B^{\prime}$ and the maximum characteristic root $\left(\lambda_{\text {max }}^{\prime}\right)$ obtained from characteristic equation $\left(B^{\prime} W=\lambda_{\text {max }}^{\prime} W\right)$ is bigger than $\mathrm{n}$, and the bigger $\lambda_{\text {max }}^{\prime}$ is, the more serious the inconsistent degree of $B^{\prime}$ is. In this situation, the characteristic vector corresponding to $\lambda_{\text {max }}^{\prime}$ is not a true reflection of the influence weight of indicators $\left(B=\left\{B_{1}, B_{2}, \ldots \ldots, B n\right\}\right)$ in this hierarchy to the indicator in the upper hierarchy. The following indicators need to be calculated in order to check the consistency ofHierarchical single arrangement:

Consistency indicator:

$$
C I=\frac{\lambda_{\max }-n}{n-1}(2)
$$

If $C I \neq 0$, the maximum characteristic root is expected to be slightly bigger than $\mathrm{n}$ and the other characteristic roots are expected to be close to 0 , then, the judgment matrix is considered to be consistent. In order to provide specific measure indicator, the mean random consistency

\begin{tabular}{|l|l|l|}
\hline 5 & 7 & 9 \\
\hline
\end{tabular}

indicator $(R I)$ is introduced to judge whether the judgment matrix is consistent.

Mean random consistency indicator:

$$
C R=\frac{C I}{R I}(3)
$$

The values of mean random consistency indicators can be found in Table 3[14].

Table 3.Mean random consistency indicator.

\begin{tabular}{|c|c|c|c|c|c|c|c|c|c|}
\hline $\mathrm{n}$ & 1 & 2 & 3 & 4 & 5 & 6 & 7 & 8 & 9 \\
\hline $\mathrm{RI}$ & 0 & 0 & 0.58 & 0.90 & 1.12 & 1.24 & 1.32 & 1.41 & 1.45 \\
\hline
\end{tabular}

When $C R<0.10$, the hie rarchical single arrangement is considered to be consistent, otherwise, adjustments should be made for the judgment matrix. In the case of $n=1$ or $2, C R$ is only formal and it needs no checking.

\subsection{Consistency check of Hierarchical total arrangement}

For obtaining the combination weights of indicators in a certain hierarchy to the highest goal and the interaction between these indicators and the indicator in the upper hierarchy, the weights of indicators in this hierarchy are calculated by using the arrangement results and the combination weights of the indicators in the upper hierarchy. In other words, the weights of all indicators in a certain hierarchy to the highest goal are calculated, which is called hierarchical total arrangement.

There are $m$ indicators $\left(A_{1}, A_{2}, \ldots \ldots, A m\right)$ in hierarchy $A$, and the weights are $a_{1}, a_{2}, \cdots \cdots, a_{m}$ respectively. There are $n$ indicators $\left(B_{1}, B_{2}, \ldots \ldots, B n\right)$ in the lower hierarchy $B$, the hierarchical single arrangement weights of them are known as $b_{1 j}, b_{2 j}, \ldots \ldots, b n j$. If $B_{k}$ is not relevant with $A_{j}$, then $b_{k j}=0$. The hierarchical total arrangement weights can be obtained by following the hierarchical total arrangement matrix shown in Table 4.

Table 4.Hierarchical total arrangement weights of hierarchy B

\begin{tabular}{|c|c|c|c|c|c|c|c|}
\hline & $A_{l}$ & $A_{2}$ & $\cdots \cdots$ & $A_{j}$ & $\cdots \cdots$ & $A_{m}$ & $\begin{array}{c}\text { Weight of } \\
\text { hierarchy }\end{array}$ \\
\cline { 2 - 7 } & $a_{1}$ & $a_{2}$ & $\cdots \cdots$ & $a_{j}$ & $\cdots \cdots$ & $a_{m}$ & $\sum_{\mathrm{j}=1}^{\mathrm{m}} \mathrm{a}_{\mathrm{j}} \mathrm{b}_{1 \mathrm{j}}$ \\
\hline$B_{1}$ & $b_{11}$ & $b_{12}$ & $\cdots \cdots$ & $b_{1 j}$ & $\cdots \cdots$ & $b_{1 m}$ & $\sum_{\mathrm{j}=1}^{\mathrm{m}} \mathrm{a}_{\mathrm{j}} \mathrm{b}_{2 \mathrm{j}}$ \\
\hline
\end{tabular}




\begin{tabular}{|c|c|c|c|c|c|c|c|}
\hline$\cdots \cdots$ & $\cdots \cdots$ & $\cdots \cdots$ & $\cdots \cdots$ & $\cdots \cdots$ & $\cdots \cdots$ & $\cdots \cdots$ & $\cdots \cdots$ \\
\hline$B_{n}$ & $b_{n 1}$ & $b_{n 2}$ & $\cdots \cdots$ & $b_{n j}$ & $\cdots \cdots$ & $b_{n m}$ & $\sum_{\mathrm{j}=1}^{\mathrm{m}} \mathrm{a}_{\mathrm{j}} \mathrm{b}_{\mathrm{nj}}$ \\
\hline
\end{tabular}

Hie rarchical total arrangement consistency indicator of hierarchy $B$ is shown as Equation 4, where $C I j$ is hierarchical single arrangement consistency indicator of hierarchy $B$ to indicator $A j$, and $R I j$ is mean random consistency indicator of hierarchy $\mathrm{B}$ to indicator $A j$.

$$
C R=\frac{\sum_{j=1}^{m} a_{j} C I_{j}}{\sum_{j=1}^{m} a_{j} R I_{j}}(4)
$$

Similarly, hierarchical total arrangement is consistent if $C R<0.10$. Otherwise, judgment matrix needs adjustments.

\subsection{Indicator combination weight calculation}

The geometric method[15]can be adopted in the calculation of matrix weight. The steps are as follows:

(1) Calculate the product of all elements in every row in the judgment matrix:

$$
m_{i}=\prod_{i=1}^{n} b_{i j}(i=1,2 \ldots n)(5)
$$

(2) Calculate $n$-th root of mi $\left(\overline{\omega_{l}}=\sqrt[n]{m_{i}}\right)$ :

$$
\omega_{\mathrm{i}}=\overline{\omega_{1}} / \sum_{\mathrm{j}=1}^{\mathrm{n}} \overline{\omega_{\mathrm{j}}}(6)
$$

(3) Calculate the maximum characteristic root $\left(\lambda_{\max }\right)$ of matrix B:

$$
\lambda_{\max }=\frac{1}{\mathrm{n}} \sum_{\mathrm{i}=1}^{\mathrm{n}}(\mathrm{B} \omega)_{\mathrm{i}} / \omega_{\mathrm{i}}(7)
$$

The weight of indicator hierarchy can be calculated with the weight of criterion hierarchy $B$. Assuming that the relative weight of criterion hierarchy $B$ to goal hierarchy $A$ is $\bar{\omega}=\left(\overline{\omega_{1}}, \overline{\omega_{2}}, \ldots . \overline{\omega_{\mathrm{k}}}\right)^{\mathrm{T}}$, and the relative weight of indicator hierarchy $C$ to criterion hierarchy $B i$ is $\bar{\omega}=\left(\omega_{1 \mathrm{i}}, \omega_{2 \mathrm{i}}, \ldots \ldots, \omega_{\mathrm{ni}}\right)^{\mathrm{T}}$, then the relative weight (Wi) of indicator hierarchy $C$ to goal hierarchy $A$ can be obtained:

$\mathrm{W}_{1}=\sum_{\mathrm{j}=1}^{\mathrm{k}} \omega_{\mathrm{j}} \omega_{1 \mathrm{j}} \quad, \quad \mathrm{W}_{2}=\sum_{\mathrm{j}=1}^{\mathrm{k}} \omega_{\mathrm{j}} \omega_{2 \mathrm{j}} \quad, \ldots \ldots, \quad \mathrm{W}_{\mathrm{n}}=$ $\sum_{\mathrm{j}=1}^{\mathrm{k}} \omega_{\mathrm{j}} \omega_{\mathrm{nj}}$.

\section{Determination of Anhui inland port facilities adaptability evaluation indicator weight}

In the process of researching upgrading strategy of Anhui inland simple backward port facilities, port facilities adaptability evaluation system should be established to evaluate the adaptability for all the port facilities, and judge their development level to lay the theoretical foundation for proposing the batch-upgrading scheme. Several representative indicators are chosen from those initial indicators when establishing port facilities adaptability evaluation system. These representative indicators should cover every criterion hierarchy, and the starting point is "keep to the point" and "from point to area", which is significant in choosing relatively important and representative indicators.

AHP is adopted to deal with expert scoring data, and MATLAB functions and matrix calculation are used in the input and creation of judgment matrix with loop structure to checking the consistency of judgment matrix. The weights of all indicators in indicator hierarchy to the goal hierarchy are calculated when the judgment matrix is consistent. The program flow chart of AHP is shown as Figure.2. The weights of indicators of criterion hierarchy (port classification throughput and capacity) and the checking result of single arrangement consistency are shown in Table 5, and the final weights of all the indicators are shown in Table 6.

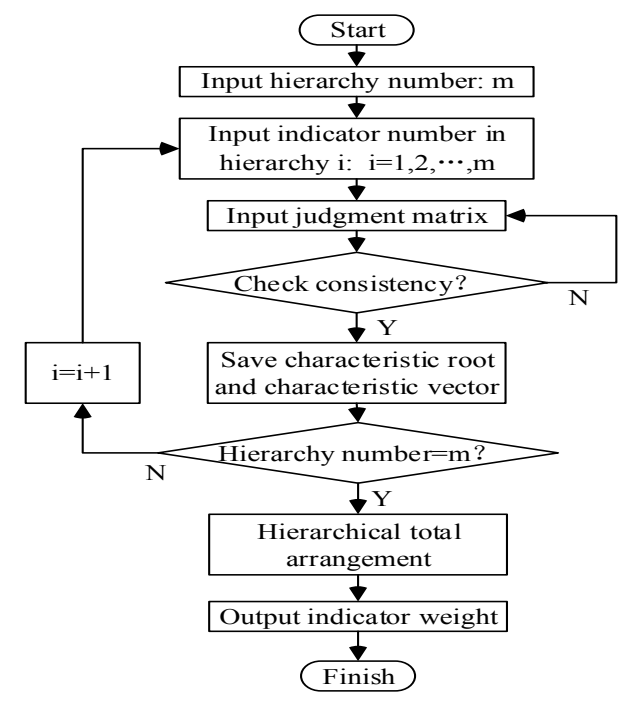

Figure 2.Program flow chart of AHP.

According to the calculation results listed in Table 6, in criterion hierarchy, port economy, port classification throughput and capacity, port coastline efficiency and port energy consumption are the 4 indicators that have 
most influence on port facilities adaptability evaluation, which also means they determine port development level. In indicator hierarchy, profit margin of the cost and expense, port throughput, net assets return ratio and energy consumption of every 10000-ton goods mark the highest weight, and these 4 indicators reflect the essence of port facilities adaptability evaluation directly. Among these 4 indicators, profit marg in of the cost and expense, port throughput and net assets return ratio represent port economy development level, and energy consumption of every 10000-ton goods represents port energy consumption efficiency.

According to the weight values of indicators to the goal hierarchy listed in Table 6, weight contribution threshold value of these indicators to the goal hierarchy is taken as $85 \%$, and the weight contribution sum of 16 indicators whose weights are relatively larger is $86.16 \%$. $(0.1995+0.1176+0.1155+0.0560+0.0546+0.0510$ $+0.0459+0.0350+0.0320+0.0252+0.0243+0.0221+0.0221$ $+0.0221+0.0221+0.0166=86.16 \%)$. Considering the correlation analysis of these indicators, 16 evaluation indicators are chosen as follows: port safety, port usability, channel level, energy consumption of every 10000-ton goods, energy consumption of every 10000-yuan inco me, operation capacity, checked capacity, port throughput, throughput of unit shoreline length, shoreline length of every 10000-ton capacity, berth capacity utilization, berth operation rate, berth utilization, productivity of staffs, profit margin of the cost and expense and net assets return ratio.

Compare the 16 selected main valuation indicators with indicators in Table 6 , it can be found that the main evaluation indicators selected by AHP have a wide coverage: they involve 6 of the all 8 criterion hierarch ies. Moreover, these selected indicators contain main valuation contents such as port safety, port throughput, port shoreline efficiency and port economy, which means they consist of those major problems in port facilities adaptability evaluation.
The development reality of Anhui ports and quantification valuation operability of these indicators should be taken into consideration to make some fine-adjustments in the determination of port facilities adaptability valuation indicators. The fine-adjustments are helpful for the perfection of port facilities adaptability evaluation system, which makes its results provide scientific guidance for port facilities batch-upgrading scheme in the future.

\section{Conclusions and suggestions}

(1) AHP is a concise and practical decision-making method. On the basis of expert scoring, the weights of port facilities adaptability evaluation indicators can be determined. AHP is used to combine qualitative judg ment with quantitative judgment and transform a multi-criteria and multi-objective problem into a multi-hierarchy and single objective problem, whose calculation is simplex and results are clear.

(2) AHP is adopted in selecting port facilities adaptability evaluation indicators. With MATLAB programming calculation and analysis, 16 relatively important and representative evaluation indicators are chosen, which lay the foundation for establishing port facilities adaptability evaluation system in the future.

(3) The development reality of Anhui ports and quantification valuation operability of these indicators should be taken into consideration in the determination of port facilities adaptability valuation indicators. On the basis of expert scoring data, the weight of port facilities adaptability evaluation indicators are determined and port facilities adaptability evaluation indicators are selected with AHP. The research method and research results can be an essential reference for decision making of port navigation management department.

(4) A cmprehensive model such as fuzzy-AHP method are supposed to be conducted in the future to improve the quality of the evaluation system.

Table 5. Port classification throughput and capacity indicators.

\begin{tabular}{|c|c|c|c|c|c|}
\hline $\begin{array}{c}\text { Port classification } \\
\text { throughput and } \\
\text { capacity }\end{array}$ & $\begin{array}{c}\text { Designed } \\
\text { capacity }\end{array}$ & $\begin{array}{c}\text { Checked } \\
\text { capacity }\end{array}$ & $\begin{array}{c}\text { Operation } \\
\text { capacity }\end{array}$ & $\begin{array}{c}\text { Port } \\
\text { throughput }\end{array}$ & Weight: $\omega_{i}$ \\
\hline Designed capacity & 1 & $1 / 3$ & $1 / 5$ & $1 / 7$ & 0.06 \\
\hline Checked capacity & 3 & 1 & $1 / 3$ & $1 / 5$ & 0.12 \\
\hline
\end{tabular}




\begin{tabular}{|c|c|c|c|c|c|}
\hline $\begin{array}{l}\text { Operation } \\
\text { capacity }\end{array}$ & 5 & 3 & 1 & $1 / 3$ & 0.26 \\
\hline Port throughput & 7 & 5 & 3 & 1 & 0.56 \\
\hline \multicolumn{6}{|c|}{$\begin{array}{l}\lambda_{\max }=4.12 ; \mathrm{CR}=0.0438, \text { matrix is consistent } \\
\omega_{i}-\text { Normalization weight }\end{array}$} \\
\hline
\end{tabular}

Table 6. Final weights of indicators.

\begin{tabular}{|c|c|c|c|}
\hline Goal & Criterion & Indicator & Weight \\
\hline \multirow{33}{*}{$\begin{array}{l}\text { Port facilities } \\
\text { adaptability } \\
\text { valuation }\end{array}$} & \multirow{5}{*}{$\begin{array}{c}\text { Hydraulic structure } \\
0.090\end{array}$} & Berth structure and level & 0.0117 \\
\hline & & Berth depth & 0.0027 \\
\hline & & Port technical state & 0.0054 \\
\hline & & Port safety & 0.0459 \\
\hline & & Port usability & 0.0243 \\
\hline & \multirow{2}{*}{$\begin{array}{c}\text { Channel and ship } \\
\text { type } \\
0.022\end{array}$} & Channel level & 0.0166 \\
\hline & & Ship type & 0.0034 \\
\hline & \multirow{4}{*}{$\begin{array}{c}\text { Port classification } \\
\text { throughput and } \\
\text { capacity } \\
0.208\end{array}$} & Designed capacity & 0.0126 \\
\hline & & Checked capacity & 0.0252 \\
\hline & & Operation capacity & 0.0546 \\
\hline & & Port throughput & 0.1176 \\
\hline & \multirow{8}{*}{$\begin{array}{l}\text { Handling operation } \\
0.046\end{array}$} & Classification loading machinery allocation & 0.0020 \\
\hline & & $\begin{array}{c}\text { Classification loading machinery capacity and } \\
\text { production }\end{array}$ & 0.0030 \\
\hline & & Loading machinery property and technical state & 0.0050 \\
\hline & & Loading efficiency & 0.0100 \\
\hline & & Ship average efficiency & 0.0050 \\
\hline & & Ship average amount & 0.0050 \\
\hline & & Time of loading a designed ship & 0.0100 \\
\hline & & $\begin{array}{l}\text { Time of ship in port when loading every } 100 \text {-ton } \\
\text { goods }\end{array}$ & 0.0100 \\
\hline & \multirow{3}{*}{$\begin{array}{l}\text { Port energy } \\
\text { consumption } \\
0.096\end{array}$} & Energy consumption in loading goods & 0.0120 \\
\hline & & Energy consumption of every 10000 -y uan income & 0.0320 \\
\hline & & Energy consumption of every 10000 -ton goods & 0.0560 \\
\hline & \multirow{9}{*}{$\begin{array}{c}\text { Port coastline } \\
\text { efficiency } \\
0.167\end{array}$} & Port shoreline length & 0.0034 \\
\hline & & Shoreline condition and level & 0.0085 \\
\hline & & Berth number and length & 0.0085 \\
\hline & & Berth utilization & 0.0221 \\
\hline & & Berth operation rate & 0.0510 \\
\hline & & Throughput of unit shoreline length & 0.0221 \\
\hline & & Shoreline length of every 10000 -ton capacity & 0.0221 \\
\hline & & Real value of unit coastal resource & 0.0085 \\
\hline & & Berth capacity utilization & 0.0221 \\
\hline & \multirow{2}{*}{$\begin{array}{c}\text { Port warehouse and } \\
\text { y ard }\end{array}$} & Capacity & 0.0010 \\
\hline & & Effective area & 0.0024 \\
\hline
\end{tabular}




\begin{tabular}{|c|c|c|c|}
\hline \multirow{3}{*}{0.023} & Storage quota of unit area & 0.0064 \\
\cline { 2 - 3 } & Average storage capacity & 0.0026 \\
\cline { 2 - 3 } & Average storage amount & 0.0064 \\
\cline { 2 - 3 } & Average storage period & 0.0012 \\
\cline { 2 - 3 } & \multirow{3}{*}{$\begin{array}{c}\text { Port economy } \\
0.348\end{array}$} & Productivity of staffs & 0.0350 \\
\cline { 2 - 3 } & & Profit margin of the cost and expense & 0.1955 \\
\cline { 2 - 3 } & Net assets return ratio & 0.1112 \\
\hline
\end{tabular}

\section{References}

1. Z. Chen. Port \& Waterway Engineering07,70-73(2009).

2. J. Guo, Z.Zhang, Q. Sun.China Safety Science Journal.05,148-153(2008).

3. Mabrouki C, Bentaleb F, Mousrij A. Safety Sci63(3):124-132(2014).

4. P. Zhang, J. Mao, L. Yang. Software Engineering and Knowledge Engineering: Theory and Practice.943-949(2012).

5. Y. Xie, Y.Liu, X. Xiao. Frontiers of Structural and Civil Engineering.9(1), 65-70(2015).

6. G.Chen, Y. Zheao.Journal of Shanghai Jiaotong University.40(4), 701-704(2006).

7. Moghadam M K, Bonsall S, Wang J, et al. Mar. Technol. Soc. J, 43(3), 34-50(2009).

8. Dai J S L L J. Transportation Planning \& Technology,
35(4), 509-524(2012).

9. Chiu R, Lin L, Ting S. Math ProblEng, 37(3), 413-418(2014).

10. F. Zhu. International Conference on Management \& Service Science, 1-4 (2011).

11. X.Zhou, H. Lin. China Water Transport,12,68-70(2008).

12. Z.Wang, X.Li.. Port \& Waterway Engineering, 02, 81-85(2001).

13. X.Wang, L.Qin, Y.Chen.Journal of Chongqing Jiaotong University(Natural Science), 04,628-631(2010).

14. X. WANG, Q. Kang, J.Qin, Q. Zhang, S. Wang. Journal of Central South University (Science and Technology), 06, 2455-2462(2013).

15. Saaty, T L, Wong M M. J. MathSociol, 9,181-209(1993). 